\title{
Critical Analysis and the Impact of Big Data within the Organisation
}

\author{
Tefo Sekgweleo ${ }^{1, *}$, Phathutshedzo Makovhololo ${ }^{1,2}$ \& Modikwa Luwi Makovhololo ${ }^{2,3}$ \\ ${ }^{1}$ Department of Infomatics, Cape Peninsula University of Technology, Cape Town, South Africa \\ ${ }^{2}$ Department of Infomatics, Tshwane University of Technology, Pretoria, South Africa \\ *Correspondence: Department of Infomatics, Cape Peninsula University of Technology, Cape Town, South Africa. \\ E-mail: ts330ci@gmail.com
}

Received: December 10, 2019

Accepted: December 27, 2019 Online Published: February 17, 2020

doi:10.5430/mos.v6n2p30

URL: https://doi.org/10.5430/mos.v6n2p30

\begin{abstract}
Currently in the advancement of big data, the challenges for many organisations are not technologically related. The biggest barrier relates to cultural challenges which include organizational alignment, resistance or lack of understanding as well as change management. As a result, many organizations are purely not ready to take advantage of this new strategic resource called big data. Therefore, big data acceptance compels addressing the above mentioned challenges that falls within the domains of technology, people as well as organization. Thus, this study employed diffusion of innovation theory to assess the cultural challenges in an organization. The interpretivist approach was applied in the analysis of the data.
\end{abstract}

Keywords: big data, organizational culture, technology

\section{Introduction}

Advancement in technology has transformed the dynamic relationships of human behavior as well as the environment they live in. People make use of variety of devices which includes smart phones, mobile devices as well as computers suitable for their digital life in order to leave their digital footprint on the Internet (Tsou, 2015). Chen et al. (2013) asserted that presently, huge amounts of data are created daily in the manufacturing sectors, business, science and our personal lives. The vigorous source of online information, which consists of abundant social media messages, web sites and forum discussions, has turned out to be the crucial kind of Big Data for cartographic research (Tsou, 2015:70). On the other hand, social data can be easily accessed facebook, twitter or Instagram which could assist organizations in modifying or adjusting their business strategies. Thus, Iyamu (2018) emphasizes that organizations utilizes big data for numerous reasons which includes efficiency, sustainability as well as competitiveness. Mgudlwa and Iyamu (2018) states that regardless of the size, diversity and complexity, big data can be connected within the perspective and meaning in order to achieve the goals and objectives of the organization in any region, including healthcare and social media.

Big data comprises enormous quantity of data which makes traditional data processing complex and inadequate. With traditional data certain amount of data can be stored. However, big data can store huge volumes of data easily. Open framework such as Hadoop permits distributed processing of huge sets of data through clusters of computers utilizing simple programming models (De Mauro, Greco, \& Grimaldi, 2016). Therefore, tools are no longer a challenge for big data. A lot has been done technologically to deal with enormous volumes of data. As a result, organizations need to be very innovative in order to achieve competitiveness. Employees' attitude is very key especially in the adoption of new technology. This attribute affects how employees perform their duties and it forms part of organizational culture. The way in which people interacts with one another, clients as well as stakeholders is influenced by the organizational. According to Omerzel et al. (2016), empirical evidence indicates that organizations with more developed entrepreneurial characteristics and organizational culture are more innovative.

This research paper is separated into six main parts. The first part introduces the study. The second part discusses the literature review which explains big data, big data tools, innovation and organizational culture. The third part covers the theory that is underpinning the study namely diffusion of innovation (DoI). The fourth, fifth and the sixth part discusses the methodology, discussions and findings and recommendations respectively. Lastly is the conclusion of 
the study.

\section{Literature Review}

\subsection{Big Data}

Big data is regarded as an emerging model useful for capturing, managing and processing big datasets within acceptable and tolerable time which cannot be achieved through common traditional software tools (Xu, Liu, Mei, $\mathrm{Hu}, \&$ Chen, 2015). In addition, De Mauro, Greco and Grimaldi (2015:122) posited that, "the term 'Big Data' is used to describe a wide range of concepts: from the technological ability to store, aggregate, and process data, to the cultural shift that is pervasively invading business and society, both drowning in information overload". Hence Dumbill (2013) asserts that data is considered Big when its processing capability exceeds the one of traditional database systems and requires a substite for processing it.

The proponents of big data indicated that, in the age of big data massive datasets consist of semi or unstructured data, such as Facebook posts, tweets, uploaded pictures and videos, and blogs, and some estimates suggest that such data is growing 15 times more than the rate of structured data with advances in database design and machine learning techniques aiding storage and analysis (Zikopoulos et al., 2012; Kitchin, 2014). Big data is also generated from the accumulative variety of sources including internet clicks, mobile transactions, user-generated content as well as purposefully generated content through sensor networks or business transactions such as sales queries and purchase transactions (George, Haas, \& Pentland, 2014).

According to Xu, Liu, Mei, Hu, and Liu (2015) big data is characterized by three aspects: (a) data is numerous, (b) data cannot be categorized into regular relational databases, and (c) data is generated, captured, and processed rapidly. They (Xu, Liu, Mei, Hu, \& Chen, 2015) further indicate that big data evaluation is driven by fast-growing cloud-based applications developed using virtualized technologies. Moreover, big data has gained much attention from researchers in healthcare, bioinformatics, and information sciences (Manogaran \& Lopez, 2017).

\subsection{Big Data Tools}

It is quite evident that big data technologies are becoming the most common area of focus and a new "buzz-word" both in science and in industry marking the start of a new form of the continuous technology advancement (Demchenko, Grosso, De Laat, \& Membrey, 2013). This emergence is characterized by overlapping technology waves related to different aspects of the human activity from production and consumption to collaboration and general social activity. Chen and Zhang (2014) posited that, web-based applications encounter big data frequently, such as recent hot spots social computing (including social network analysis, online communities, recommender systems, reputation systems, and prediction markets), Internet text and documents, Internet search indexing.

Though there are many existing technologies and tools involved the big data arena, for the purpose of this study the researchers only did examination of Hadoop. Hadoop is one of the open source project introduced and hosted by Apache Software Foundation consisting of many small sub projects which belong to the category of infrastructure for distributed computing (Katal, Wazid, \& Goudar, 2013). Banks need Hadoop to perform risk analysis on their customer's profile. For instance, different type of data gets presented in the banking and financial institutes and this type of data are very sensitive and important due to its privacy. Therefore, this data needs better management and Hadoop is perceived to be capable of managing this data (Singh, \& Singla, 2015).

In their studies, Katal et al. (2013) mentioned that, Hadoop mainly consists of: x File System (The Hadoop File System) x Programming Paradigm (Map Reduce) and the other subprojects provide complementary services, or they are building on the core to add higher-level abstractions. Singh and Singla (2015) argued further indicating that HBase helps to store large amount of data in a very efficient way because it is a non-relational column oriented database and it is built at the top of Hadoop.

\subsection{Innovation}

Innovation is a method that ought to be driving change in the way organisations conduct their day-to-day business. According to Rogers (2003) innovation is regarded "as an idea, practice, or project that is perceived as new by individual or other unit of adoption. Behrens, Berger, Hud, Hünermund, Iferd, Peters, Rammer and Schubert (2017), described innovation as a key driver of productivity and market growth and thus has a great potential for increasing wealth. Corso and Pavesi (2000) asserted that "innovation is a continuous and cross functional process of learning and improvement involving and integrating a growing number of competencies inside and outside the organisational boundaries". 
Central component in the processes of gaining and sustaining competitive advantage is proclaimed to be driven by ability of the corporate to innovate (Foss, Laursen, \& Pedersen, 2011). Ivanová and Čepel (2018) argued that at the corporate level, one of the significant factors for increasing competitiveness is the ability to implement innovation in a proper timeframe, and better work organization. Therefore, it is imperative to mention that innovation remain one of the critical elements within the corporate that drives the success and to foster opportunities for competitive advantage.

\subsection{Decision Making}

According to Baker et al. (2001), decision making should start with the identification of the decision maker(s) and stakeholder(s) in the decision, reducing the possible disagreement about problem definition, requirements, goals and criteria. There are many factors that contribute in the way in which decisions are made (Croft, 2013). These can be influenced by past experience, individual differences and cognitive biases (Bruine de Bruin, Parker, \& Fischhoff, 2007; Juliusson, Karlssson, \& Gärling, 2005; West, Toplak, \& Stanovich, 2008). Because decision making is a core activity for professional regulators, most of its high-impact regulatory decisions are often made in an uncertain environment. Regulators can draw on a range of tools and techniques to strengthen their organizational decision making processes to address these challenges (Cox, Strang, Sondergaard, \& Monsalve, 2017). According to Sheperd (2011), there are many studies that attempted to explain how organizations make decisions.

Decision making ranges from strategic decisions through to managerial decisions and routine operational decisions and is at the core of planning (Al-Tarawneh, 2012). However, decision making is not just about selecting the right choices or compromises. Unless a decision has 'degenerated into work', it is not a decision. It is at best a good intention (Drucker, 1967). Effective decision making is defined here as the process through which alternatives are selected and then managed through implementation to achieve business objectives. Decision-making is a problem-solving process which ends when a satisfying solution is reached. The process of decision-making is done on the bases of culture, perceptions, belief systems, values, attitudes, personality, knowledge, and the insight of the decider(s) (Delazer, 2011; Ratcliff, Philiastides, \& Sajda, 2009).

\subsection{Organisational Culture}

Organizational culture refers to a system of shared assumptions, values, and beliefs that show people what is appropriate and inappropriate behavior (Chatman, \& Cha, 2003). Culture is largely invisible to individuals just as the sea is invisible to the fish swimming in it. Even though it affects all employee behaviors, thinking, and behavioral patterns, individuals tend to become more aware of their organization's culture when they have the opportunity to compare it to other organizations (Mohammed, 2017). The culture of the organization from a national culture perspective originates from the work done by Deal and Kennedy (1982). Deal and Kennedy (1982) viewed the organizational culture as significant to organizational success rather than factors such as structure, strategy or politics. Because of this view, there was a shift focus from the national cultures and more on the organizational culture. As stated above, Arnold (2005:625) posit that "organizational culture is the distinctive norms, beliefs, principles and ways of behaving that combine to give each organization its distinct character". For some, culture is considered the "glue" that holds an organization together and for others, the "compass" that provides directions (Tharp, 2009).

Organizational culture differentiates the extraordinarily successful organisation from all the rest (Manetje, 2005). It can be a powerful, competitive advantage. The organizations' culture is always distinct, but the big winners, consistently make culture a priority in the organizations (Van Rooij \& Fine, 2018). Organizations hire culture specialists to provide survey tools which evaluates negative elements in their corporate culture (Lubin, 2017). It is no longer enough to focus on bad things, but such bad things has to be addressed (Scholten \& Ellemers 2016; Pertiwi, 2018). Survey conducted by Bain \& Company in 2007 concerning worldwide business leaders indicated that business culture is as important as business strategy for business succeed (Ana, Ferreras, Lesia, \& Crumpton-Young, 2017). It is not a surprise that the success of the organization relies on the organizational culture. According to the Organizational Culture Profile framework organizations with innovative cultures are usually flexible, easy-going, and tryout new ideas.

\section{Methodology}

There are various research approaches that can be adopted when conducting a research. They include quantitative, qualitative and mixed method approaches. According to Connelly (2016), qualitative research approach enables researchers to fully depict the deeper meaning of the phenomenon to increase the readers' understanding. Flick (2018) further asserted that qualitative approach assists in examining peoples' reports for their subjective opinions, attitudes, 
beliefs or reflections on their experiences of things in the outer world. Lin (2009) stated that literature research approach assists researchers to ultimately access information from a diversity of literature sources which is commonly denoted as "non-contact method". Dotong and Laguador (2015) affirm that literature review approach allows researchers to read, examine and categorise literatures to find the critical feature of materials. For the purpose of this research paper, qualitative and literature research approaches were adopted. A number of peer reviewed journals including chapter in books were reviewed. The researchers discovered the importance of organizational culture regarding the adoption of new technology in order to be innovative.

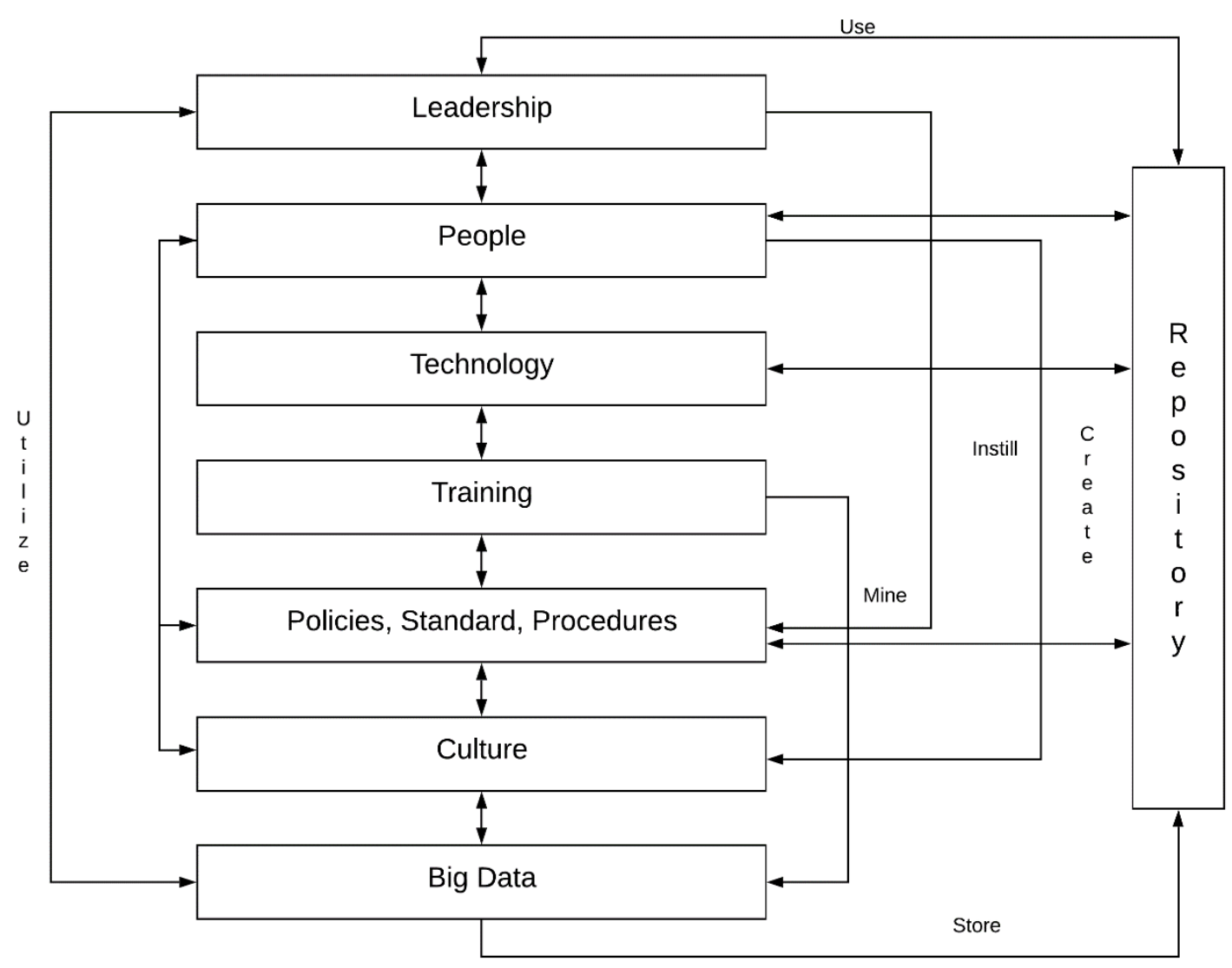

Figure 1. Factors Influencing Organizational Culture

\section{Discussions and Findings}

\subsection{Leadership}

As data is becoming increasingly important, management is required to step-in to coach its people about the importance of data. Therefore, business leadership teams who are assigned to create organizational strategy, needs to work hand in hand with data scientists who are able to provide them with knowledge to stimulate choices that would create competitive edge. It is of high importance to benefit from understanding data because it lowers risk for loosing business and increase organizational productivity. Embracing data-driven decision making for the future can assist organizations to remain relevant at all times and to be competitive. Therefore, the full adoption of this practice needs to be pioneered by managers because it will finally manifest into the organizational culture and all the employees will have to support it.

Organizations have entrusted managers with a leadership role. Their responsibility is to oversee departments or group of employees within the organization and to effectively communicate with coworkers. As a result, they have the authority and powers to direct and groom their subordinates to become productive and fulfill the organizational strategy. Leadership provides the ability to enable the management structure to operate effectively. Thus, managers contribute substantially across all divisions and such is revealed through organizations profits as well as employees 
morale.

However, at times managers are faced with various challenges. The implementation of big data can be a challenge, depending which leadership style is followed within the organization. The major challenge faced by the organizations is to make big data work linked to people and not technology. It entails concerns such as organizational positioning, change management and process adoption. Adjusting to new technology occurs progressively but it depends on how organizational culture is instilled. Big data should be accepted by top management first and the employees/subordinates would follow suite. To ensure that big data is understood and accepted at all levels, IT departments need to organize many trainings and workshops so that employees can have the understanding of what they are dealing with. To realize the acceptance of big data, its adoption and the use of new big data solution need to be monitored and controlled. However, the management need not overdo the control because it may have an adverse effect.

\subsection{People}

The big data and related technologies are useless if human analysis is completely left out. Smart technologies may afford faster as well as accurate results but may fail to uncover specific insight. For example, patient doctor's diagnosis might essentially provide facts to evaluate the patient's health for a longer period. However, this is impossible when technologies make diagnosis because there is no previous data. Big data can be knowlegeable when both human instinct and social sciences is taken into consideration. This is due to reasons such as behavior and varied cultural magnitude. Human behavior is influenced by several factors such as genetic make-up, culture, individual values as well as attitudes. While on the other hand, cultural diversity is made up of a group of various personalities from diverse societies. Ordinarily, diverse culture recognizes language, belief, ethnic group, gender and age. Therefore, culture is conceived out of how people behave within the community or organization. Thus, organizations have started to embrace corporate diversity because people spend most of their time at work. This was due to the changing workforce.

\subsection{Training}

Creating a data-driven culture for the organization is more than just having a team of data scientists. To enable data scientists to do their job, management must be willing to invest time and money into building infrastructure, acquiring technology and providing relevant business leadership training. This includes a management team that understands the methods of big data, data analytics and data science. Most importantly, management must understand that the results are only as good as the decision makers themselves. Since the future of work revolves around data, organization-wide access to data and insights must be provided to facilitate decision making. Then, decision makers do not have to wait for analysis or reports by the data science team. With the data exposed to more employees, more perspectives could increase fresh and groundbreaking insights on a given business challenge.

Lastly, management must direct the whole effort of managing data science towards problem-solving endeavors. Data analysis provides insights that must be acted upon to make the process worthwhile.

\subsection{Big Data Repository}

Data repository is the destination designated to store data. It is a tool where data is mined for analysis and reporting. The repository itself is the setup of databases that is used to gather, store and manage varying datasets. This works because data provides the information and evidence businesses/organizations need to make decisions. When organizations' wants to grow and develop in business, they analyse large datasets to help make reasonable and acceptable business decisions. As information from digital platforms grows, so does the data storage capacity. Therefore, organizations are required to invest money into relevant tools and infrastructure to store and mine its data. It is the responsibilities of the organizations to also train its employees on the tools they purchase for data mining in order diligently utilize those tools.

During early stages of computing, the type of data which was stored used to be text and amounts. However, lately data is stored as audio, pictures, photographs and film. These types of data are stored in binary format. There are pricise methods to decode data amid binary language as well as interpreting it. Organizations store its data such as policies, standards and procedures, employee's data as well its clientele data. As a result, this data is used for business decisions to enable organizations to remain competitive. Data forms the possible realm in which people live daily. Big data analytics assists organizations in harnessing the use of data to ascertain fresh opportunities. As a result, it leads to good business changes, effective processes, profitability and customer satisfaction. 


\subsection{Technology}

Technology is dynamic and keeps on advancing. Throughout the years technology has advanced and has changed how people live. For example, banking and shopping can be done online, communication is much simpler as it is done through mobile phones, skype, video conferencing and social media, also travelling from one place to the other is quicker. All these things are possible due to continuous technological advancements. When peoples' demands and how they live change, advancement in technology is required. Things that people use, has been innovated to better the standards of living. Technological advancements have assisted organizations and businesses to save time and cost of production. As a result, organizations managed to gain competitive advantage through these advancements. For example, business has benefited from the use of $3 \mathrm{G} / 4 \mathrm{G}$ broadband to reach their customers at low cost. The market is engulfed with a range of big data tools. They include IBM SPSS Modeler, R-Programming, Hadoop, Elasticsearch, Lumify, Apache SAMOA, Plotly, Spark, Splice Machine, Talend, Skytree, Microsoft HDInsight, Hive and etc.

The cost of the above tools is reasonable and they are efficient in simplifying data analytical tasks. This software can be extensively utilized to provide eloquent analysis for big dataset. It also assists in discovering up-to-date market trends and customer likings. However, it is important to know that the consequences of the advancement of technology as it can be good or bad. On a good node, technological progression has improved on how things are done. It has improved communication, production and enabled people to save time. On a bad node, technological progression has made people sluggish, it has made technology users reliant on tools, it increased health risks due to people exercising less and it has negatively impacted the environment due to growth in pollution which results into global warming. In education, students can no longer think but depend on calculators to resolve mathematical problems. As a result, they can't use their brains to solve simple tasks.

\subsection{Organizational Policies, Standards and Procedures}

Policies are the code of action that is adopted by the organization and supported by the management. These policies should reflect the objectives of the big data program. Organizational policies are like the building foundation which makes the organization to be strong and unshaken. Policies are developed with the intention of being in place for numerous years and are frequently reviewed with approved changes made as required. On the other hand standards are compulsory rules that support policies. One of the difficult things in writing standards for big data program is to get a company-wide consent on what standards need to be put in place. It can be such a time-consuming process but is important for the success of big data program.

Procedures are detailed step by step instructions to achieve a given goal or mandate. They are typically intended for internal departments and should adhere to strict change control processes. Procedures can be developed as you go. If this is the route your organization chooses to take it's necessary to have comprehensive and consistent documentation of the procedures that you are developing. Therefore, policies, standards and procedures are created to support the objectives of the organization. They ultimately get embedded within the organizational culture. All this is possible through the support of senior management.

\subsection{Organizational Culture}

As data becomes progressively important, organizations must embrace the changing business environment by adding relevant leadership. As such, managers will be able to enforce policies, standards and procedures to achieve the objectives of the organization. Polices, standards and procedures, force the employees to abide by them which in turn creates the organizational culture. Therefore, to efficiently make a shift within the organization, human leadership needs to be properly planned, in order to make the right decisions which are aligned to the business requirements. Building the great organizational culture plays the essential part not only to the employee engagement but to meeting the business objectives. Organizations need to evaluate their employee's performance, analyse business outcomes and market trends, create new policies in order to lead and stay ahead of its rivals. As a result, organizations will be able to discover reasons for the employee dissatisfaction and be able to benchmark against its rivals. Employees, irrespective of whether they are at a management level or not, must be given the same importance as the managers.

Big data tools can assist juniors employees make collaborative business decisions with their managers. Large amounts of data that organizations have, assists data analysts to find patterns in the data which helps to gain actionable insights. Predictive analytics can assist organizations to predict the market trends, set business objectives, create policies to enhance the way they do business. However, big data in the organization can have a negative impact. Analysis of policies, market trends, business objectives, requires the organization to have a large dataset containing relevant data. Inadequate data can give wrong predictions, which could be disadvantageous to the organization. Managers need to be at the fore front of creating a culture that includes all the employees. All 
employees should feel that they are making an effective contribution to the prosperity of the organization.

\section{Conclusion}

To gain value added competition, it is critical that organization should start fostering learning and invest in their employees as currently most of the organizations are shifting towards a data-based decision-making approach. It is of vital importance for organizations to send their employees on significant training relating to analytical tools that will strengthen their teams with relevant and up to date knowledge and skills needed to utilize data in order to make informed decisions. Firstly, organizations need to be data driven in order to properly utilize big data for altering decision making as well as shifting the mindset and culture. Organizations have a chance of utilizing data analytics to be more competitive and flexible in strategizing and making decisions. It is imperative for organizations to understand the significance of data analytics so that they could invest data analytics tools and its employees to take advantage of this opportunity. Organizations need to build data driven culture in order for it to be profitable and competitive.

\section{References}

Al-Tarawneh, H. A. (2012). The main factors beyond decision making. Journal of Management Research, 4(1), 1-23. https://doi.org/10.5296/jmr.v4i1.1184

Behrens, V., Berger, M., Hud, M., Hünermund, P., Iferd, Y., Peters, B., Rammer, C., \& Schubert, T. (2017). Innovation activities of firms in Germany-Results of the German CIS 2012 and 2014: Background report on the surveys of the Mannheim Innovation Panel Conducted in the Years 2013 to 2016. Zew Dokumentationen, 17(4), $1-208$.

Bruine de Bruin, W., Parker, A. M., \& Fischhoff, B. (2007). Individual differences in adult decision-making competence. Journal of personality and social psychology, 92(5), 938-956. https://doi.org/10.1037/0022-3514.92.5.938

Chatman, J. A., \& Cha, S. E. (2003). Leading by leveraging culture. California management review, 45(4), $20-34$. https://doi.org/10.2307/41166186

Chen, C. P., \& Zhang, C. Y. (2014). Data-intensive applications, challenges, techniques and technologies: A survey on Big Data. Information sciences, 275, 314-347. https://doi.org/10.1016/j.ins.2014.01.015

Chen, J., Chen, Y., Du, X., Li, C., Lu, J., Zhao, S., \& Zhou, X. (2013). Big data challenge: a data management perspective. Front. Computer Science, 7(2), 157-164. https://doi.org/10.1007/s11704-013-3903-7

Connelly, L. M. (2016). Trustworthiness in qualitative research. Medsurg Nursing, 25(6), 435-437.

Corso, M., \& Pavesi, S. 2000. How management can foster continuous product innovation. Integrated Manufacturing Systems, 11(3), 199-211. https://doi.org/10.1108/09576060010320443

Cox, K., Strang, L., Sondergaard, S., \& Monsalve, C. G. (2017). Understanding how organisations ensure that their decision making is fair. RAND Europe. https://doi.org/10.7249/RR1827

Croft, K. (2013). The role of heuristics in entrepreneurial decision-making. Doctoral dissertation, University of Pretoria.

Delazer, M., Zamarian, L., Bonatti, E., Walser, N., Kuchukhidze, G., Bodner, T., Benke, T., Koppelstaetter, F., \& Trinka, E. (2011). Decision making under ambiguity in temporal lobe epilepsy: Does the location of the underlying structural abnormality matter? Epilepsy \& Behavior, 20(1), 34-37. https://doi.org/10.1016/j.yebeh.2010.11.006

De Mauro, A., Greco, M., \& Grimaldi, M. (2016). A formal definition of Big Data based on its essential features. Library Review, 65(3), 122-135. https://doi.org/10.1108/LR-06-2015-0061

De Mauro, A., Greco, M., \& Grimaldi, M. (2015). What is big data? A consensual definition and a review of key research topics. AIP conference proceedings, 1, 97-104. https://doi.org/10.1063/1.4907823

Demchenko, Y., Grosso, P., De Laat, C., \& Membrey, P. (2013). Addressing big data issues in scientific data infrastructure. International Conference on Collaboration Technologies and Systems (CTS) IEEE. 48-55. https://doi.org/10.1109/CTS.2013.6567203 
Dotong, C. I., \& Laguador, J. M. (2015). Philippine Quality Assurance Mechanisms in Higher Education towards Internationalization. Studies in Social Sciences and Humanities, 3(3), 156-167.

Drucker, P. F. (1967). Effective Decisions. Harvard University. Graduate school of business administration.

Dumbill, E. (2013). Making sense of big data. Journal Impact Factor, 1(1), 1-2. https://doi.org/10.1089/big.2012.1503

George, G., Haas, M. R., \& Pentland, A. (2014). Big data and management. Academy of Management Journal, 57(2), 321-326. https://doi.org/10.5465/amj.2014.4002

Ferreras, A. M., \& Crumpton-Young, L. L. (2017). Company Success in Manufacturing Organizations: A Holistic Systems Approach. CRC Press. https://doi.org/10.1201/9781315118314

Flick, U. (2018). An introduction to qualitative research. Sage Publications Limited.

Foss, N. J., Laursen, K., \& Pedersen, T. (2011). Linking customer interaction and innovation: The mediating role of new organizational practices. Organization Science, 22(4), 980-999. https://doi.org/10.1287/orsc.1100.0584

Ivanová, E., \& Čepel, M. (2018). The impact of innovation performance on the competitiveness of the Visegrad 4 countries. Journal of Competitiveness, 10(1), 54-72. https://doi.org/10.7441/joc.2018.01.04

Iyamu, T. (2018). A multilevel approach to big data analysis using analytic tools and actor network theory. South African Journal of Information Management, 20(1), 1-9. https://doi.org/10.4102/sajim.v20i1.914

Juliusson, E. Á., Karlsson, N., \& Gärling, T. (2005). Weighing the past and the future in decision making. European Journal of Cognitive Psychology, 17(4), 561-575. https://doi.org/10.1080/09541440440000159

Katal, A., Wazid, M., \& Goudar, R. H. (2013). Big data: issues, challenges, tools and good practices. In 2013 Sixth international conference on contemporary computing (IC3), 404-409. https://doi.org/10.1109/IC3.2013.6612229

Lin, G. (2009). Higher Education Research Methodology-Literature Method. International Education Studies, 2(4), 179-181. https://doi.org/10.5539/ies.v2n4p179

Lubin, J. S. (2017). After Uber andWells Fargo, BoardsWake up to Culture. Wall Street Journal.

Mgudlwa, S., \& Iyamu, T. (2018). Integration of social media with healthcare big data for improved service delivery. South African Journal of Information Management, 20(1), 1-9. https://doi.org/10.4102/sajim.v20i1.894

Mohammed, J. I. (2017). An assessment of the impact of organizational culture on employee performance. International Journal of Development and Management Review, 12(1), 178-183.

Manogaran, G., \& Lopez, D. (2017). A survey of big data architectures and machine learning algorithms in healthcare. International Journal of Biomedical Engineering and Technology, 25(2-4), 182-211. https://doi.org/10.1504/IJBET.2017.087722

Omerzel, D. G.., Nastav, B., Köves, A., Király, G., Pataki, G., Balázs, B., Gatarik, E., Born, R., Kocjančič, J., Bojnec, Š., \& Ehrenstorfer, B. (2016). Managing Global Transitions. International Research Journal, 14(1), 1-113.

Pertiwi, K. (2018). Contextualizing Corruption: A Cross-Disciplinary Approach to Studying Corruption in Organizations. Administrative Sciences, 8(2), 12. https://doi.org/10.3390/admsci8020012

Ratcliff, R., Philiastides, M. G., \& Sajda, P. (2009). Quality of evidence for perceptual decision making is indexed by trial-to-trial variability of the EEG. Proceedings of the National Academy of Sciences, 106(16), 6539-6544. https://doi.org/10.1073/pnas.0812589106

Rogers, E. M., Singhal, A., \& Quinlan, M. M. (2003). Diffusion of innovations. New York: Simon and Schuster.

Scholten, W., \& Ellemers, N. (2016). Bad apples or corrupting barrels? Preventing traders' misconduct. Journal of Financial Regulation and Compliance, 24(4), 366-382. https://doi.org/10.1108/JFRC-06-2016-0051

Shepherd, D. A. (2011). Multilevel entrepreneurship research: Opportunities for studying entrepreneurial decision making. Journal of Management, 37(2), 412-420. https://doi.org/10.1177/0149206310369940

Singh, J., \& Singla, V. (2015). Big data: tools and technologies in big data. International Journal of Computer Applications, 112(15), 6-10. https://doi.org/10.5120/ijca2015907553

Tharp, B. M. (2009). Defining "culture" and "organizational culture": From anthropology to the office. Interpretation a Journal of Bible and Theology, Harworth, 7 . 
Tsou, M. H. (2015). Research challenges and opportunities in mapping social media and Big Data. Cartography and Geographic Information Society, 42(1), 70-74. https://doi.org/10.1080/15230406.2015.1059251

Van Rooij, B., \& Fine, A. (2018). Toxic corporate culture: assessing organizational processes of deviancy. Administrative Sciences, 8(23), 1-38. https://doi.org/10.3390/admsci8030023

West, R. F., Toplak, M. E., \& Stanovich, K. E. (2008). Heuristics and biases as measures of critical thinking: Associations with cognitive ability and thinking dispositions. Journal of Educational Psychology, 100(4), 930. https://doi.org/10.1037/a0012842

Xu, Z., Liu, Y., Mei, L., Hu, C., \& Chen, L. (2015). Semantic based representing and organizing surveillance big data using video structural description technology. Journal of Systems and Software, 102, 217-225. https://doi.org/10.1016/j.jss.2014.07.024

Zikopoulos, P., Deroos, D., Parasuraman, K., Deutsch, T., Giles, J., \& Corrigan, D. (2012). Harness the power of big data The IBM big data platform. McGraw Hill Professional. 